ARTICLE

Received 25 Feb 2015 | Accepted 8 May 2015 | Published 16 Jun 2015

DOl: $10.1038 /$ ncomms8451

OPEN

\title{
Rh D blood group conversion using transcription activator-like effector nucleases
}

\author{
Young-Hoon Kim², ${ }^{1,}$, Hyun O. Kim ${ }^{3}$, Eun J. Baek ${ }^{4}$, Ryo Kurita ${ }^{5}$, Hyuk-Jin Cha ${ }^{6}$, Yukio Nakamura ${ }^{7}$ \\ \& Hyongbum $\mathrm{Kim}^{1,2}$
}

Group O D-negative blood cells are universal donors in transfusion medicine and methods for converting other blood groups into this universal donor group have been researched. However, conversion of D-positive cells into D-negative is yet to be achieved, although conversion of group A or B cells into O cells has been reported. The Rh D blood group is determined by the RHD gene, which encodes a 12 -transmembrane domain protein. Here we convert Rh D-positive erythroid progenitor cells into D-negative cells using RHD-targeting transcription activator-like effector nucleases (TALENs). After transfection of TALENencoding plasmids, RHD-knockout clones are obtained. Erythroid-lineage cells differentiated from these knockout erythroid progenitor cells do not agglutinate in the presence of anti-D reagents and do not express $D$ antigen, as assessed using flow cytometry. Our programmable nuclease-induced blood group conversion opens new avenues for compatible donor cell generation in transfusion medicine.

\footnotetext{
${ }^{1}$ Graduate School of Biomedical Science and Engineering/College of Medicine, Hanyang University, Seoul 133-791, South Korea. ${ }^{2}$ Department of Pharmacology, Brain Korea 21 Plus Project for Medical Sciences, Graduate Program of Nano Science and Technology, Yonsei University College of Medicine, Seoul 120-752, South Korea. ${ }^{3}$ Department of Laboratory Medicine, Yonsei University College of Medicine, Seoul 120-752, South Korea. ${ }^{4}$ Department of Laboratory Medicine, Hanyang University College of Medicine, Seoul 133-791, South Korea. ${ }^{5}$ Department of Research and Development, Central Blood Institute, Japanese Red Cross Society, Tokyo 135-8521, Japan. ${ }^{6}$ Department of Life Sciences, College of Natural Sciences, Sogang University, Seoul 121-742, Korea. ${ }^{7}$ Division of Cell Engineering, RIKEN BioResource Center, Tsukuba, Ibaraki 305-0074, Japan. Correspondence and requests for materials should be addressed to H.K. (email: hkim1@yuhs.ac).
} 
B lood group systems are important for blood transfusion. In clinical transfusion, the $\mathrm{ABO}$ and $\mathrm{Rh} \mathrm{D}$ blood group systems are the most critical among 33 human blood group systems that have been identified (http://www.isbtweb.org/workingparties/red-cell-immunogenetics-and-blood-group-terminology/ blood-group-terminology). Because type $\mathrm{O} \mathrm{Rh} \mathrm{D}$-negative blood cells are universal donors for transfusion, attempts have been made to convert other blood groups into type $\mathrm{O}$ by enzymatically removing antigenic carbohydrates ${ }^{1-4}$. The ABO blood group type is determined by a glycosyltransferase activity that attaches $\alpha$-N-acetylgalactosamine (for group A) or $\alpha$-D-galactose (for group $\mathrm{B}$ ) to the $\mathrm{H}$ antigen on the surface of red blood cells. Furthermore, specific exoglycosidases that cleave these bonds between carbohydrate moieties are available and can convert type A or B cells into type $\mathrm{O}$ cells ${ }^{1-4}$. However, because the Rh D group is determined by the expression of the RHD protein on blood cells rather than by the activity of certain enzymes, such enzymatic manipulations are not a desirable approach for the conversion of $\mathrm{Rh} \mathrm{D}$-positive into D-negative cells, which is yet to be achieved.

The $\mathrm{Rh} \mathrm{D}$ blood system was discovered in 1940 (ref. 5) and, since then, a number of other $\mathrm{Rh}$ antigens have been identified. $\mathrm{D}$ is the most immunogenic and clinically important among 50 well-defined antigens in the Rh system ${ }^{6}$. D antigenicity is determined by the RHD protein, a 12-transmembrane domain protein encoded by $R H D$, a gene on chromosome 1 (refs 7,8). Roughly $85 \%$, 95\% and more than $99.5 \%$ of Caucasians, black Africans and east Asians are D-positive, respectively ${ }^{9}$. The main cause of the D-negative phenotype in Caucasians is the homozygous deletion of the whole $R H D$ gene ${ }^{10}$. In Africans, RHD deletion is also the most common mechanism of $D$-negativity, but $\sim 67 \%$ of $D$-negative Africans have at least one copy of $R H D^{\star} \Psi$, an $R H D$ allele inactivated by a 37-bp duplication at the intron 3 -exon 4 boundary, which may generate a frameshift and premature termination codon (PTC), and a nonsense mutation in exon 6 (ref. 11). Most people are D-positive or -negative, although a minor fraction of the population are $\mathrm{D}$-variants, with phenotypes that include weak $\mathrm{D}$, partial $\mathrm{D}$ and $\mathrm{DEL}^{12}$.

The $\mathrm{D}$ antigen poses a danger for $\mathrm{Rh} \mathrm{D}$-negative people. Because those who are Rh D-negative do not have naturally occurring antibodies against the $\mathrm{D}$ antigen, adverse effects may not occur when an $\mathrm{Rh} \mathrm{D}$-negative person is first exposed to $\mathrm{Rh}$ D-positive cells through blood transfusion or by giving birth to an $\mathrm{Rh}$ D-positive baby. After such an initial exposure, however, an $\mathrm{Rh} \mathrm{D}$-negative person can develop anti-Rh $\mathrm{D}$ antibodies, which can induce immune responses against $\mathrm{Rh} \mathrm{D}$-positive cells. When the $\mathrm{Rh} \mathrm{D}$-negative person is again exposed to $\mathrm{Rh} \mathrm{D}$-positive cells, these immune responses can cause adverse effects including haemolysis or abortion of subsequent D-positive babies. The ability to convert $\mathrm{Rh} \mathrm{D}$-positive into $\mathrm{Rh} \mathrm{D}$-negative cells could provide a starting point for the development of a potential therapeutic modality for these problems.

Programmable nucleases, which include zinc-finger nucleases (ZFNs), transcription activator-like effector nucleases (TALENs) and RNA-guided engineered nucleases (RGENs), enable targeted genetic modifications in cells and organisms ${ }^{13}$. The scope of programmable nuclease-based genome editing covers gene disruptions, insertions, point mutagenesis (or correction) and chromosomal rearrangements such as large deletions, inversions, duplications and translocations. Gene knockout or disruption is the simplest form of programmable nuclease-based genome editing and can be achieved by making a double-stranded break in a specific locus using only one or one pair of programmable nucleases in the absence of donor template. Programmable nuclease-induced double-stranded breaks can be repaired through error-prone nonhomologous-end joining, which often leads to the generation of small insertions or deletions, allowing gene disruption. We have previously used ZFNs, TALENs and RGENs to disrupt protein-coding genes in various human cells ${ }^{14-18}$.

We postulated that programmable nuclease-based editing of blood group-determining genes could lead to blood-group conversion. As a proof-of-concept study, here we disrupted $R H D$ in $\mathrm{Rh}$ D-positive human erythroid progenitor cells using two different pairs of TALENs. $R H D$-knockout erythroid progenitor cells were obtained and gave rise to erythroid-lineage cells that show an $\mathrm{Rh} \mathrm{D}$-negative cell phenotype in flow cytometry and agglutination tests. These data provide evidence that blood group conversion can be achieved using programmable nuclease-based gene editing.

\section{Results}

Design and validation of TALENs targeting $R H D$. To completely disrupt the RHD gene, we first obtained a TALEN pair that targets upstream of the protein-coding region; a TALEN pair targeting exon 1 was prepared (RHD_E1_TALENs; Fig. 1a). We next determined that this exon 1 target sequence is included in all transcript variants. Transcript information from NCBI and Ensembl showed that the human RHD gene has collectively 10 transcript variants including two that do not produce proteins (Supplementary Fig. 1). Exon 4 is included in all eight coding sequences, whereas exon 1 is included in seven coding sequences. Furthermore, exon 4 is the mutation locus of $R H D$ in some $\mathrm{Rh}$ D-negative people ${ }^{11}$. Thus, we also designed TALENs that target exon 4 (RHD_E4_TALENs; Fig. 1a).

To validate the activity of the designed TALENs, we transfected plasmids encoding them into HEK293T cells and performed a T7E1 assay. The mutation frequencies at the target sites in $R H D$ exons 1 and 4 were $12 \%$ and $6 \%$, respectively (Fig. 1b,c), indicating that both pairs of TALENs have activity at the target sites.

Generation of clones containing RHD mutations. We next attempted to use these TALENs to make RHD-knockout cells from $\mathrm{Rh} \mathrm{D}$-positive erythroid progenitor cells. Our source of erythroid progenitor cells was the HiDEP-1 cell line, which is derived from induced pluripotent stem cells generated from fibroblasts from an $\mathrm{Rh} \mathrm{D}$-positive (DD) donor ${ }^{19}$. For efficient generation of knockout cells, we used a magnetic reporter plasmid that expresses $\mathrm{H}-2 \mathrm{~K}^{\mathrm{k}}$ in the presence of programmable nuclease activity at the target sequence as previously reported ${ }^{15,17,20}$ (Supplementary Fig. 2). Three days after co-transfection with the reporter plasmid and plasmids encoding RHD_E1_TALENs or RHD_E4_TALENs, H-2 $\mathrm{K}^{\mathrm{k}}+$ HiDEP-1 cells were magnetically separated ${ }^{15,20}$ and seeded into 96-well plates for dilution cloning at an average density of 0.25 cells per well (Fig. 2a). Individual clones were isolated 17 days after the clonal cell seeding; genomic DNA was isolated from each clone and analysed. For efficient screening of mutant clones, genomic DNA from three (RHD_E1_TALENs) or four (RHD_E4_TALENs) clones was grouped, mixed and subjected to the T7E1 assay. This group T7E1 assay showed that six out of seven clone groups from the RHD_E1_TALEN-transfected cells and nine out of thirty-seven clone groups from the RHD_E4_TALEN-transfected cells included at least one mutant clone (Supplementary Fig. 3). Each individual clone in these positive clone groups was then subjected to the T7E1 assay. In cells transfected with RHD_E1_TALENs, this screening identified 9 mutant clones out of 20 total (Supplementary Fig. 3; Fig. 2b). Subsequent sequencing analysis showed that these nine clones comprise seven monoallelic out-of-frame mutant clones, 
1 monoallelic in-frame mutant clone ( 3 nucleotide deletion), and 1 biallelic mutant clone that contains one in-frame mutation (6 nucleotide deletion) and one out-of-frame mutation (2 nucleotide deletion)(Supplementary Fig. 4a). Because in-frame mutations can lead to incomplete gene knockout, we attempted to obtain biallelic out-of-frame mutant clones. For this purpose, we again co-transfected the reporter plasmid and the plasmids encoding RHD_E1_TALENs into one (\#17) of the 7 monoallelic out-of-frame mutant clones and performed clonal culture after magnetic separation. Sequencing of DNA from 7 subclones derived from this monoallelic mutant clone showed that all the subclones contain the 2 nucleotide deletion that was initially observed in the parent clone. Among the 7 subclones, one subclone (\#17-3), which contained biallelic out-of-frame mutations, was designated as E1_B (\#17-3; Supplementary Fig. 4b) and expanded for additional study.

Similarly, in cells co-transfected with the reporter plasmid and the plasmid encoding RHD_E4_TALENs, the two-step T7E1 assay revealed that 7 out of 148 clones contain mutations near the target sites in exon 4 (Supplementary Fig. 3; Fig. 2b). Sequencing showed that these seven clones comprise four monoallelic inframe mutant clones (\#33, \#37, \#53 and \#122), one monoallelic out-of-frame mutant clone (\#8) and two biallelic out-of-frame mutant clones (\#5, \#118; Supplementary Fig. 4c). One of the two biallelic mutant clones and the monoallelic out-of-frame mutant clone were designated as E4_B (\#5) and E4_M (\#8), respectively, and expanded for further experiments.
We next examined the sequencing results to determine whether the selected mutant clones have PTCs in RHD exons. Both RHD alleles of clone E1_B had PTCs within exon 1 (Fig. 3a). In clone E4_B, PTCs were observed in exon 4 of one allele and in exon 5 of the other (Fig. 3b). In clone E4_M, a PTC was in exon 4 of one mutated allele (Fig. 3c). We have indicated the locations of the PTCs in a two-dimensional (2D) model of the RHD protein in Supplementary Fig. 5. Taken together, these results indicate that the RHD protein will be expressed in clone E4_M but not in E1_B or E4_B.

Off-target mutations in the mutant clones. We investigated whether the RHD-mutant clones contain off-target mutations induced by the TALEN pairs. Potential off-target sites were predicted using a web-based programme called PROGNOS (Predicted Report Of Genome-wide Nuclease Off-target Sites) ${ }^{21}$ (Supplementary Data set 1) and the two top ranking sites for RHD_E1_TALENs and the three top ranking sites for RHD_E4_TALENs were chosen for further analysis. For both TALEN pairs, the highest ranking off-target sites were in the RHCE gene, which has high homology with the RHD gene $\mathrm{g}^{22}$. The potential off-target site for the RHD_E1_TALENs in RHCE showed a perfect match with the target sequence; the T7E1 assay revealed mutations at that off-target site in the E1_B clone (Supplementary Fig. 6a). Sequencing of that region in the E1_B clone showed six sequences with a three-nucleotide deletion and

a

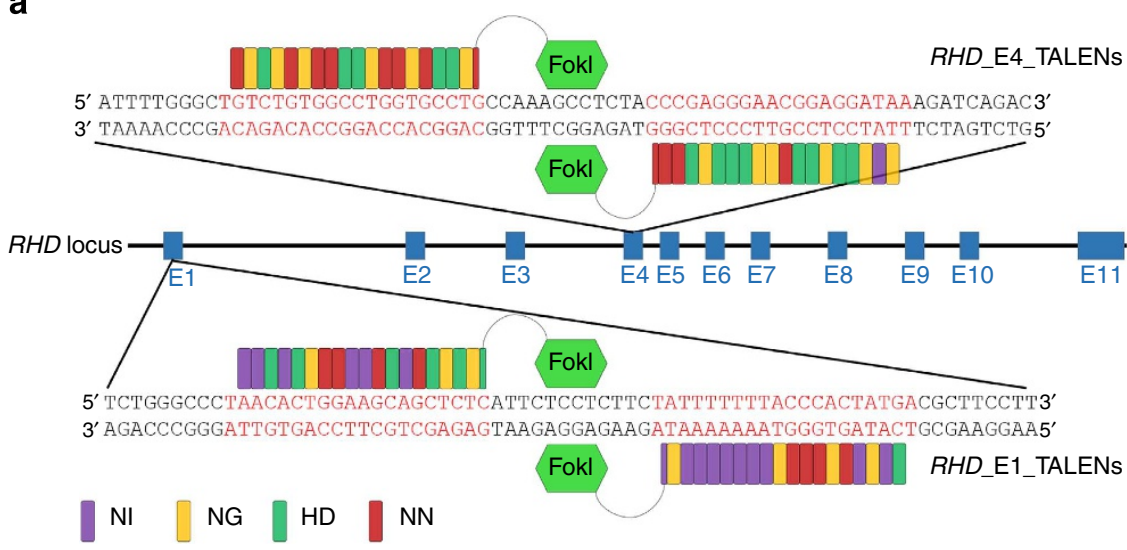

b

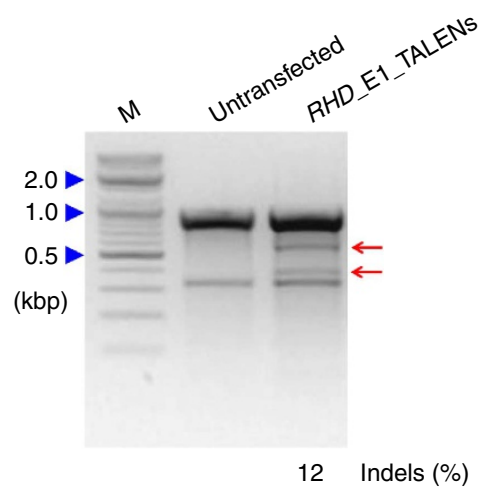

C

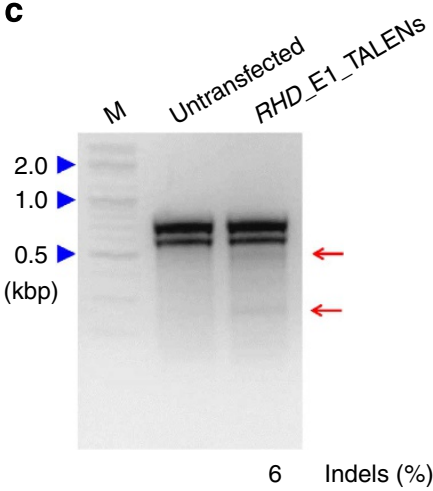

Figure 1 | TALENs targeting the human RHD gene. (a) Schematic of the TALEN-targeting sites in the RHD gene. Blue boxes indicate exons. RHD_E1_TALENs and RHD_E4_TALENs represent the TALEN pairs that target sequences (shown in a red colour) in exon 1 and exon 4 , respectively. The red, yellow, green and purple rectangular boxes in the TALENs symbolize the TALE repeat units that recognize guanine, thymine, cytosine and adenine, respectively. (b,c) T7E1 assay using 293T cells after transfection with plasmids encoding TALENs targeting RHD exon 1 (b, RHD_E1_TALENs) or exon 4 (c, RHD_E4_TALENs), respectively. The sizes of marker $(\mathrm{M})$ bands are shown on the left (kbp, kilobase pairs). Arrows indicate the expected positions of DNA bands cleaved by T7E1. The numbers at the bottom of the gel indicate mutation percentages measured by band intensities. 
a

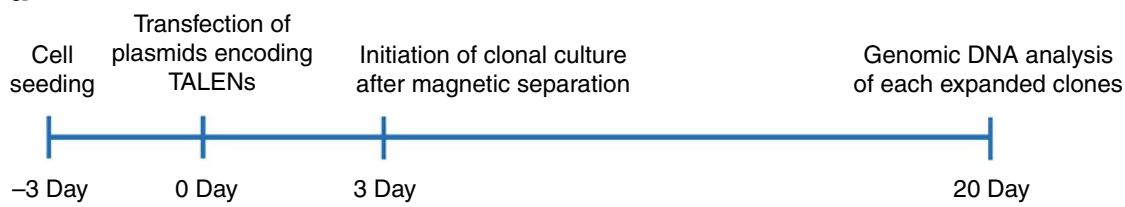

b

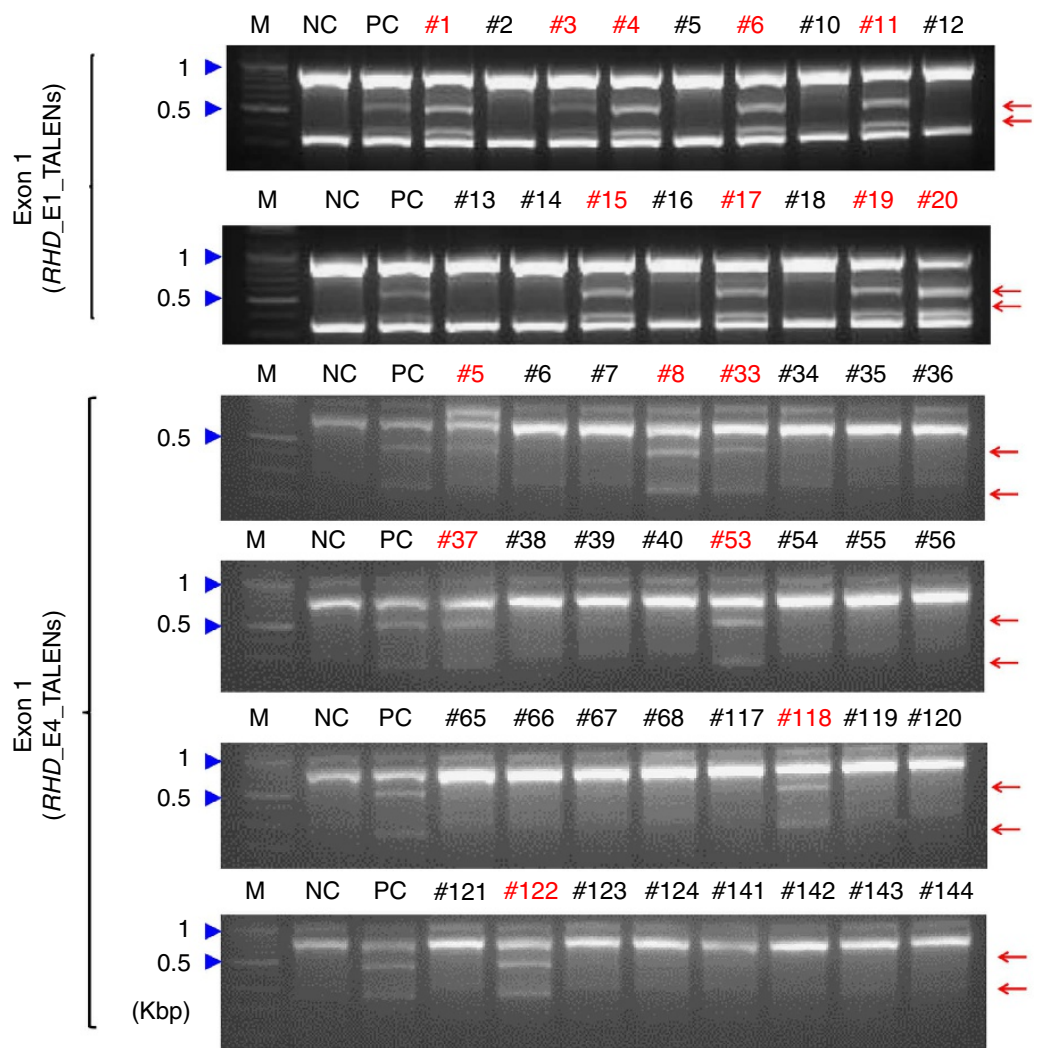

Figure 2 | Generation of RHD-mutated erythroid progenitor cells. (a) Schematic representation illustrating the process of RHD-mutated clone generation. Clonal culture of HiDEP-1 erythroid progenitor cells was initiated 3 days after transfection with plasmids encoding TALENs that target RHD. Genomic DNA from each clone was analysed 17 days after the initiation of clonal culture. (b) T7E1-based clonal analysis. The genomic DNA isolated from each clone was subjected to the T7E1 assay. Arrows indicate the expected position of DNA bands cleaved by T7E1. The sizes of marker (M) bands are shown on the left ( $k b p$, kilobase pairs). Clones containing mutations in the target sites were marked with red clone numbers. Untransfected cells and a cell population transfected with the TALEN plasmids were used as the negative control (NC) and positive control (PC), respectively. M: Markers

four sequences with another three-nucleotide deletion, suggesting biallelic heterogeneous in-frame deletions at the RHCE locus (Supplementary Fig. 6b). The potential off-target site for the RHD_E4_TALENs in RHCE had a two base pair mismatch as compared with the target sequence; the T7E1 assay revealed mutations in E4_B but not E4_M (Supplementary Fig. 6c). Sequencing of that region in clone E4_B showed five wild-type sequences and five sequences with a 16-nucleotide deletion, indicating a monoallelic mutation (Supplementary Fig. 6d). Sequencing in clone E4 revealed 10 wild-type sequences, corroborating the absence of mutations in that region. In addition, in all three analysed clones, the T7E1 assay showed no mutations at the remaining other potential off-target sites outside of the RHCE gene (Supplementary Fig. 6a,c).

RHD mRNA expression in mutant clones. We next examined RHD mRNA expression in parental, E1_B, E4_B and E4_M HiDEP-1 cells using RT-PCR. Electrophoresis of the RT-PCR products from parental HiDEP-1 cells showed a dense band at $\sim 1.4 \mathrm{~kb}$, a medium-density band at $\sim 1.3 \mathrm{~kb}$ and a weak band at $\sim 1.1 \mathrm{~kb}$ (Fig. 4a). The two higher molecular weight bands were also clearly observed in E1_B and E4_M samples as well. To identify these bands, we cloned the RT-PCR products into T-vectors and performed capillary sequencing. The results showed that transcript variant 1 , which lacks exon 8 , and a new transcript variant 1 , which lacks both exons 7 and 8 , were observed at frequencies of $8 / 19$ and $4 / 19$ in parental cells, $6 / 15$ and $4 / 15$ in E1_B and $10 / 20$ and $8 / 20$ in E4_M, respectively, accounting for the two most frequently observed transcript variants in parental $(8 / 19+4 / 19=63 \%)$, E1_B $(6 / 15+4 / 15$ $=67 \%)$ and E4_B $(10 / 20+8 / 20=90 \%$; Fig. $4 \mathrm{~b})$. Furthermore, the expected sizes of variant 1 and the new variant 1 are 1,422 and $1,288 \mathrm{bp}$, respectively. Taken together, these results indicate that the dense band at $1.4 \mathrm{~kb}$ and the medium-density band at $1.3 \mathrm{~kb}$ are variant 1 and new variant 1 , respectively, and suggest that these two transcript variants are dominant in HiDEP-1 cells.

To determine whether these RHD mRNA variants are specific to HiDEP-1 cells, an erythroid cell line derived from induced pluripotent stem cells, we performed RT-PCR using RNA from two other kinds of erythroid cells: erythroid cells differentiated from primary human cord blood $\mathrm{CD}_{3}{ }^{+}{ }^{+}$cells $^{23}$ and HUDEP-2 
a

Clone E1_B: sequences (12/12)

AGCAGCTCT ATTCTCCTCTTC PATTTTTTACCCACTATGACGCTTCCTTAGAGGATCA (Wild type)

AGCAGCTCTAATTCTCCT-TTCEATTTTTTTACCCACTATGACGCTTCCTTAGAGGATCA $(x 7) \longleftarrow$ int deletion



Allele with $1 \mathrm{nt}$ deletion

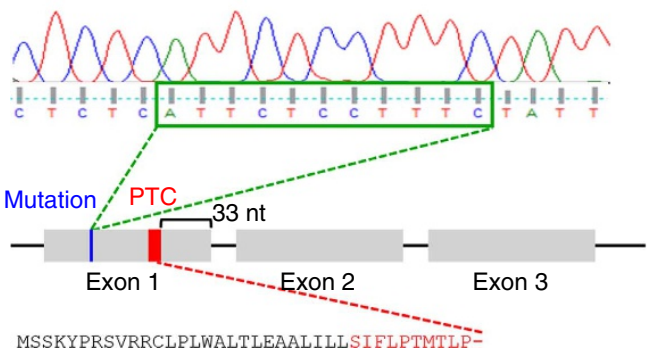

Allele with 2 nt deletion

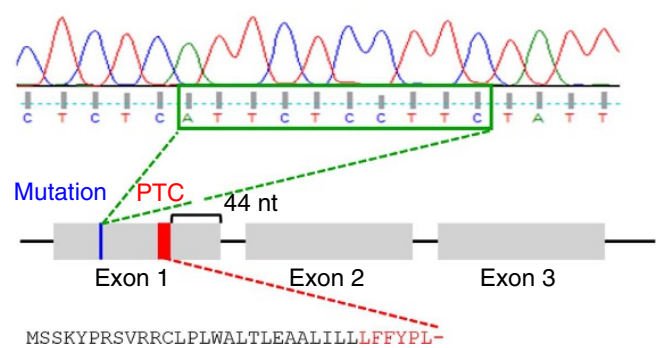

b

Clone E4_B: sequences (19/19)

TGTCTGTGGCCTGGTGCCT CCAAAGCCTCTACCGAGGGACGGAGGATAA (Wild type)

TCCACTCCACACACCCCTAAGACTCTGGATCC.GGGAGGGAACGGAGGATAA (x2)«31nt deletion, 236nt insertion

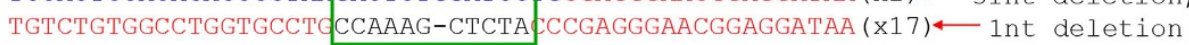

Allele with $31 \mathrm{nt}$ deletion and $236 \mathrm{nt}$ insertion

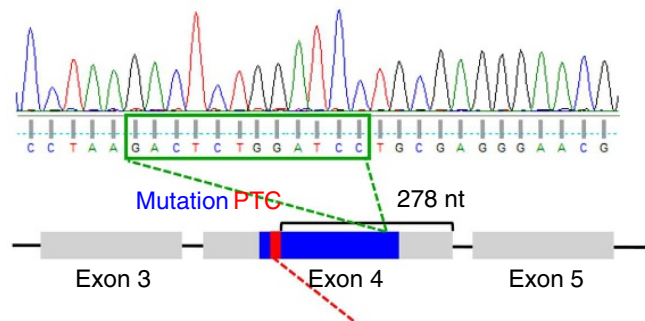

MSSKYPRSVRRCLPLWALTLEAALILLFỲ̈FFTHYDASLEDQKGLVASYQV GQDLTVMAAIGLGFLTSSFRRHSWSSVAFNLF̀YLALGVQWAILLDGFLSQ FPSGKVVITLFSIRLATMSALSVLISVDAVLGKVITLAQLVVMVLVEVTAL GNLRMVISNIFNTDYHMNMMHI YVFAAYFGLFLLSW-
Allele with 1 nt deletion

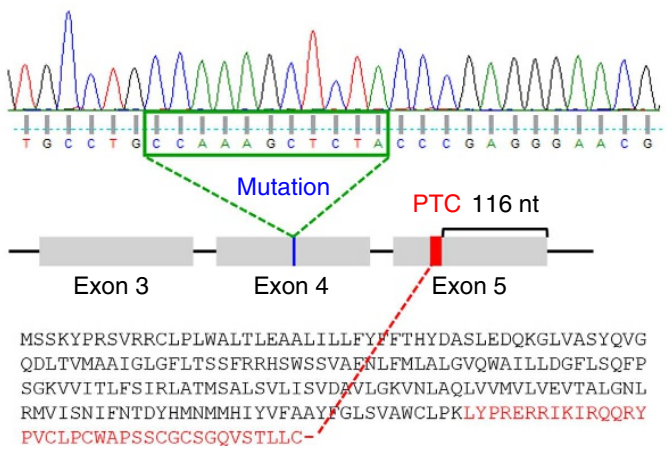

C Clone E4_M: sequences (6/6)

TGTCTGTGGCCTGGTGCCT CCAAAGCCTCTACCCGAGGAACGGAGGATAA (Wild type)

TGTCTGTGGCCT------- -- - - CTACCCAAGGGAACGGAGGATAA $(x 5) \longleftarrow 24$ nt deletion, 7 nt insertion TGTCTGTGGCCTGGTGCCTфCCAAAGCCTCTACCCGAGGGAACGGAGGATAA (x1)

Allele with $24 \mathrm{nt}$ deletion and $7 \mathrm{nt}$ insertion

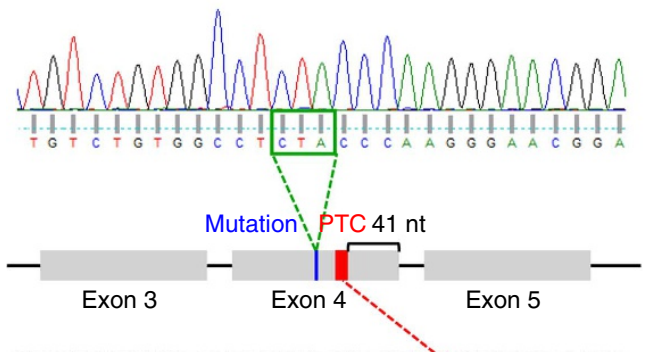

MSSKYPRSVRRCLPLWALTLEAALILLFYFFTHỲ̀ASLEDQKGLVASYQV GQDLTVMAAI GLGFLTSSFRRHSWSSVAFNLFMLALGVQWAILLDGELSQ FPSGKVVITLFSIRLATMSALSVLISVDAVLGKVNLAQLVYMVLVEVTAL GNLRMVISN IFNTDYHMNMMH I YVFAAYFGLSVASTOGNGG-
Allele with wild type sequence

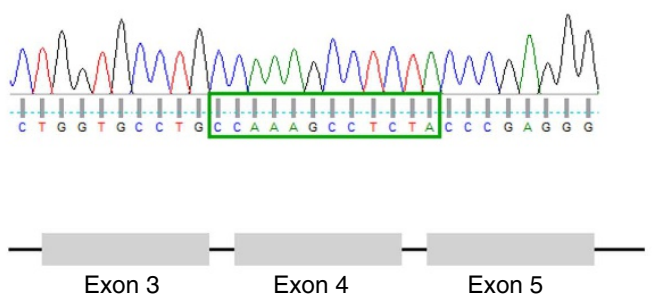

MSSKYPRSVRRCLPLWALTLEAALILLFYFFTHYDASLEDQKGLVASYQV GQDLTVMAAI GLGFLTSSFRRHSWSSVAFNLFMLALGVQWAILLDGFLSQ FPSGKVVITLFSIRLATMSALSVLISVDAVLGKVNLAQLVVMVLVEVTAL GNLRMVISNIFNTDY HMNMMHIYVFAAYFGLSVAWCLPKPLPEGTEDKDQ TAT I PSLSAMLGALFLWMFWPSFNSALLRSP IERKNAVFNTYYAVAVSVV TATSGSSLAHPQGKISKTYVHSAVLAGGVAVGTSCHLIPSPWLAMVLGLV PGCNRVLGIPHSS IMGYNFSLLGLLGEI IYIVLLVLD TVGAGNGMIGEQVLLS IGELSLAIVIALTSGLLTGLLLNLKIWKAPHEAK YFDDOVFWKFPHLAVGF-

Figure 3 | DNA sequences of RHD-mutated clones. The RHD gene DNA sequences from the parental cells, clones with biallelic mutations in exon 1 $\left(E 1 \_B ; \mathbf{a}\right)$ or exon $4\left(E 4 \_B ; \mathbf{b}\right)$, and a clone with a monoallelic mutation in exon 4 (E4_M; c). TALE-binding sites are in a red font and spacer regions are indicated with green boxes. Deleted bases are indicated by dashes and inserted bases are shown in a blue font. The number of occurrences is shown in parentheses (for example, $\times 7$ and $\times 5$ indicate the number of each sequence). The sequence and sequencing chromatogram for each allele are shown. The locus of each mutation, the PTC generated by the mutation and the distance between the PTC and the exon-intron junction are depicted in a schematic of the RHD gene. Expected protein sequence translated from each allele are displayed, such that mutated protein sequences generated by a nuclease-induced frameshifting mutation are shown in a red font and translation termination is indicated with a dash. nt, nucleotide. 
a

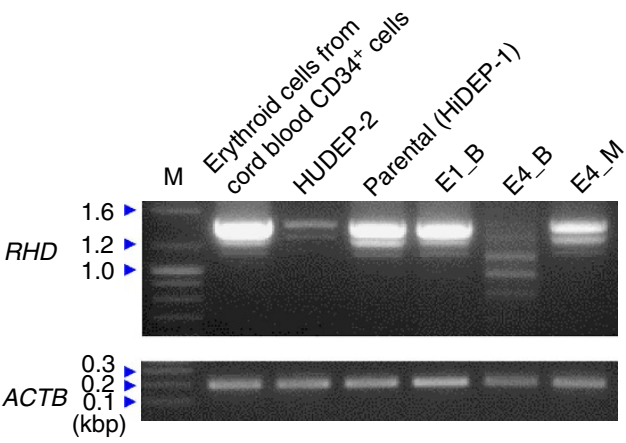

b
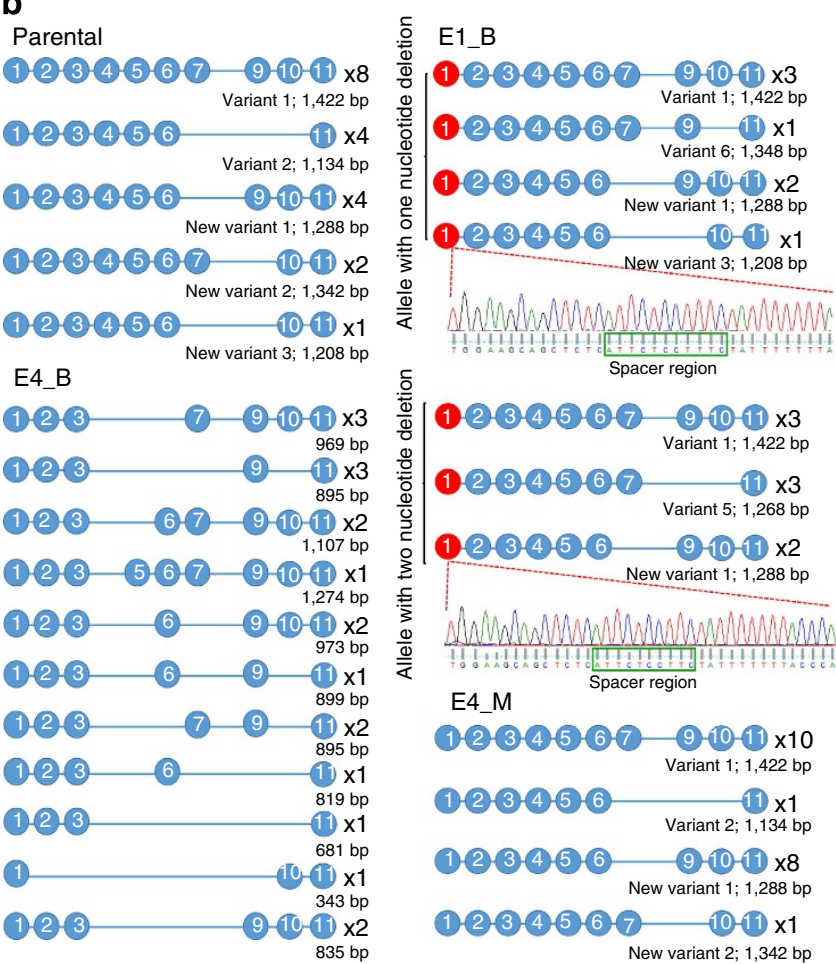

Figure 4 | RHD mRNA in the mutated clones. RT-PCR was performed to detect RHD mRNA in each clone and the amplicons were subjected to electrophoresis (a) and sequencing (b). (a) Representative pictures of electrophoresis. ACTB was used as control. The sizes of marker (M) bands are shown on the left ( $k b p$, kilobase pairs). (b) Schematic representation of $R H D$ mRNA sequences. The number of occurrences is shown on the right of each transcript. Blue and red circles indicate normal and mutated exons, respectively. For some amplicons, the sequence and sequencing chromatogram are shown (spacer regions are indicated with green boxes).

cells, an immortalized erythroid progenitor cell line derived from cord blood $\mathrm{CD}_{3}{ }^{+}$cells $^{19}$. Electrophoresis of the products from the two RT-PCRs showed the three bands, that is, a dense band at $\sim 1.4 \mathrm{~kb}$, a medium-density band at $\sim 1.3 \mathrm{~kb}$ and a weak band at $\sim 1.1 \mathrm{~kb}$, although the band at $\sim 1.1 \mathrm{~kb}$ was too faint to be observed in the HUDEP-2 mRNA (Fig. 4a). The similarity of the electrophoresis patterns of the RT-PCR products of the HiDEP-1 cells and the two different erythroid-lineage cells derived from $\mathrm{CD}_{4}{ }^{+}$cells suggests that the RHD mRNA variants observed in the parental clone are not specific to HiDEP-1 cells. Furthermore, sequencing of these RT-PCR products showed that the RHD mRNA variants observed in the parental and E1_B and E4_M clones were also observed in both cell types derived from CD34 ${ }^{+}$cells at comparable frequencies (Supplementary Fig. 7), corroborating that $R H D$ mRNA variants are not specific to cells derived from induced pluripotent stem cells.

These two bands, however, were not observed in the electrophoresis of E4_B RT-PCR products, which instead showed three weak, wide bands with a size range of $\sim 0.7 \sim 1.1 \mathrm{~kb}$. Sequencing of E4_B RHD transcripts revealed 11 transcript variants that were not observed in the other cells and have not been previously reported. Interestingly, all 11 observed transcript variants lack exon 4, the site where TALEN-induced mutations were induced. Taken together, the results indicate that the two mutations in exon 4 in clone E4_B lead to an alteration in $R H D$ RNA splicing coupled with a reduced mRNA level.

In parental, E1_B, and E4_M HiDEP-1 cells, sequencing disclosed new transcript variants that have not been previously reported; these new variants are referred to as new transcript variants 1, 2 and 3, respectively, in this manuscript. In addition, sequencing also revealed that the TALEN-induced mutation in exon 1 of each $R H D$ allele in E1_B was observed at frequencies of $8 / 15$ and $7 / 15$, respectively, indicating that the mRNAs are transcribed from both alleles and faithfully contain the mutation from each allele in the genomic DNA.

Electrophoresis showed that the RT-PCR products from E4_M (two weak bands at 1.4 and $1.3 \mathrm{~kb}$ and a very faint band at $1.1 \mathrm{~kb}$ ) were similar in size to those from unmodified cells; however, all band intensities in the E4_M samples were proportionally weaker. Sequencing showed that the transcript variant expression pattern in $\mathrm{E} 4$ _M was similar to that in unmodified cells and that the mutated sequence of one RHD allele in E4_M was not observed in mRNA. These results suggest that the majority, if not all, of the observed RHD mRNA in E4_M is expressed from the unmodified allele.

Absence of $\mathrm{D}$ antigen in the $R H D$-knockout clones. We next evaluated D antigen protein expression on each HiDEP-1 cell clone using flow cytometry. As positive and negative controls for this analysis, we used peripheral blood cells isolated from $\mathrm{Rh}$ D-positive and -negative donors, respectively. Among glycophorin $\mathrm{A}^{+}$cells, the $\mathrm{D}$ antigen expression rate was $99.96 \pm 0.004 \%$ and $1.4 \pm 0.6 \%$ in $\mathrm{Rh} \mathrm{D}$-positive and -negative blood cells, respectively (Fig. 5), suggesting that flow cytometry is a sensitive way to detect $\mathrm{D}$ antigen expression with an $\sim 1 \%$ nonspecific background signal.

Each clone was induced for differentiation towards erythrocytes for 4 days and subjected to flow cytometry. Most of the undifferentiated and differentiated HiDEP-1 cells were glycophorin $\mathrm{A}^{+}$(Supplementary Fig. 8). Among the glycophorin $\mathrm{A}^{+}$ cells, the majority of cells in the parental and monoallelic mutant clone populations showed significant $\mathrm{D}$ antigen expression (Fig. 5; Parental clone: $93 \pm 0.9 \%$, monoallelic mutant clone: $73 \pm 2 \%$ ). However, the percentage of cells expressing D antigen in the monoallelic mutant clone was significantly lower than that in the parental clone $(P<0.001$, analysis of variance (ANOVA) followed by Bonferroni's multiple comparison), indicating the monoallelic mutation reduced $\mathrm{D}$ antigen expression. The D antigen expression in the parental clone was slightly, but significantly, lower than that in the Rh D-positive blood cells $(P<0.01$, ANOVA followed by Bonferroni's multiple comparison). The two RHD biallelic mutant clones expressed $\mathrm{D}$ antigen at a level that was similar to the nonspecific background level (E1_B, $1.8 \pm 0.2 \%$; E4_B $1.4 \pm 0.1 \%$ ), suggesting the absence of $\mathrm{D}$ antigen expression in these TALEN-induced RHD-biallelic mutant clones.

Agglutination test of the RHD-knockout clones. We next performed an agglutination test, which is used for blood group 
a

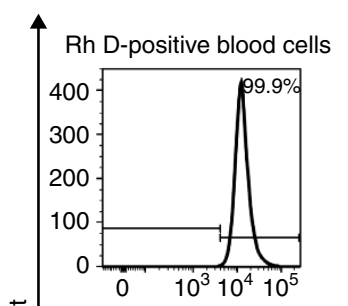

Rh D-negative blood cells

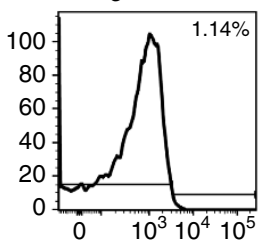

Parental HiDEP-1

(undifferentiated)

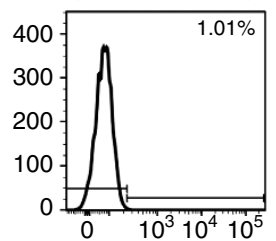

Without anti-D antibody and anti-glycophrin A antibody HiDEP-1 cells

(differentiated for 4 days)

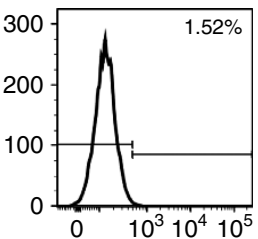

호ำ

HiDEP- 1 cells (differentiated for 4 days)

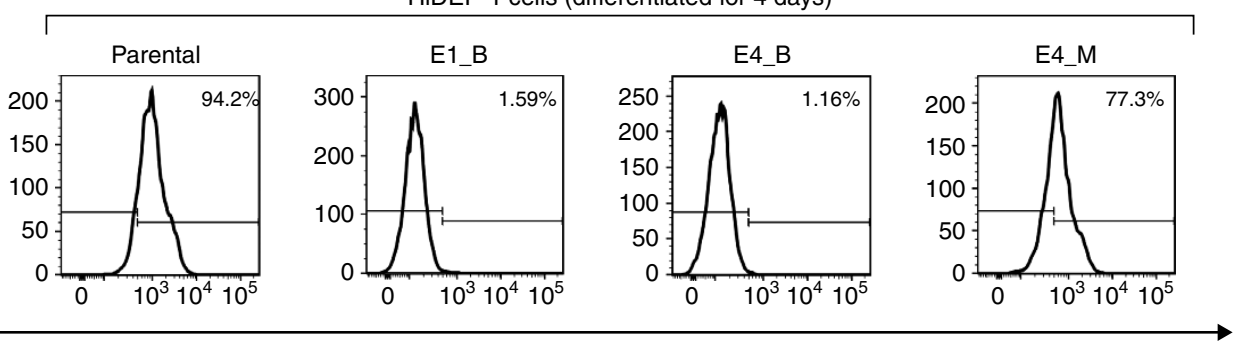

D antigen (PE)

b

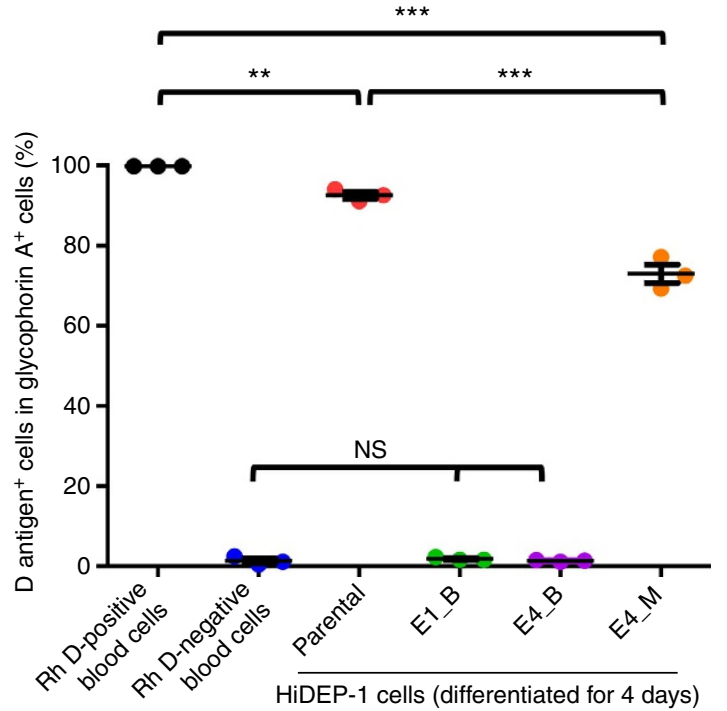

Figure 5 | Flow cytometric analysis of $\mathbf{D}$ antigen expression in mutated cells. Parental and RHD-mutated (biallelic, E1_B, E4_B; monoallelic, E4_M) HiDEP-1 cells were induced for differentiation for 4 days and subjected to flow cytometry. $D$ antigen expression was determined in glycophorin $A^{+}$cells. (a) Representative histograms. (b) The percentage of D antigen-positive cells in the population of glycophorin A-positive cells. ANOVA followed with Bonferroni's multiple comparison was performed ( ${ }^{\star \star \star} P<0.001$, ${ }^{\star \star} P<0.01$, ns $=$ not significant; $n=3$ ). Error bars represent the s.e.m.

typing. Parental, RHD-knockout (E1_B, E4_B) and RHD-monoallelic mutant (E4_M) HiDEP-1 cells were induced for differentiation for 4 days and subjected to the agglutination test using anti-D blood grouping reagents. The mixture of cells and anti-D reagent was incubated for $15 \mathrm{~min}$ at $37^{\circ} \mathrm{C}$, shaken with pipet tips and observed in 96-well plates and on glass slides. As positive and negative controls, we used $\mathrm{Rh} \mathrm{D}$-positive and -negative blood cells, which showed agglutination and no agglutination, respectively (Fig. 6a, Supplementary Fig. 9). Parental and E4_M, but not E1_B and E4_B, showed agglutination, suggesting that E1_B and E4_B are phenotypically Rh D-negative.

Weak D-positive cells, like D-negative cells, can also show 'no agglutination' by the conventional agglutination testing described above. To rule out the possibility of weak $\mathrm{D}$, we next performed a weak D detection test using E1_B and E4_B including $\mathrm{Rh} \mathrm{D}$-negative and weak D-positive blood cells as negative and positive controls, respectively. This test revealed no agglutination in either clone (Fig. 6b), demonstrating that the two $R H D$-knockout clones are D-negative rather than being weak D-positive.

Differentiation and function of the RHD-knockout clones. We evaluated whether TALEN-induced RHD knockout affects erythrocyte generation from the erythroid progenitor cells or the oxygen-carrying functions. Parental and E1_B cells were induced for differentiation into erythrocytes as previously reported by our group ${ }^{19}$. Morphological analysis showed that erythrocyte differentiation was comparable among parental, E1_B, E4_B and E4_M clones (Fig. 7a), suggesting that TALEN-induced $R H D$ knockout does not affect this process. Furthermore, the average cell size during differentiation was similar among the parental and three mutant clones (Fig. 7b), supporting that RHD knockout does not influence differentiation. Moreover, flow cytometry 
a
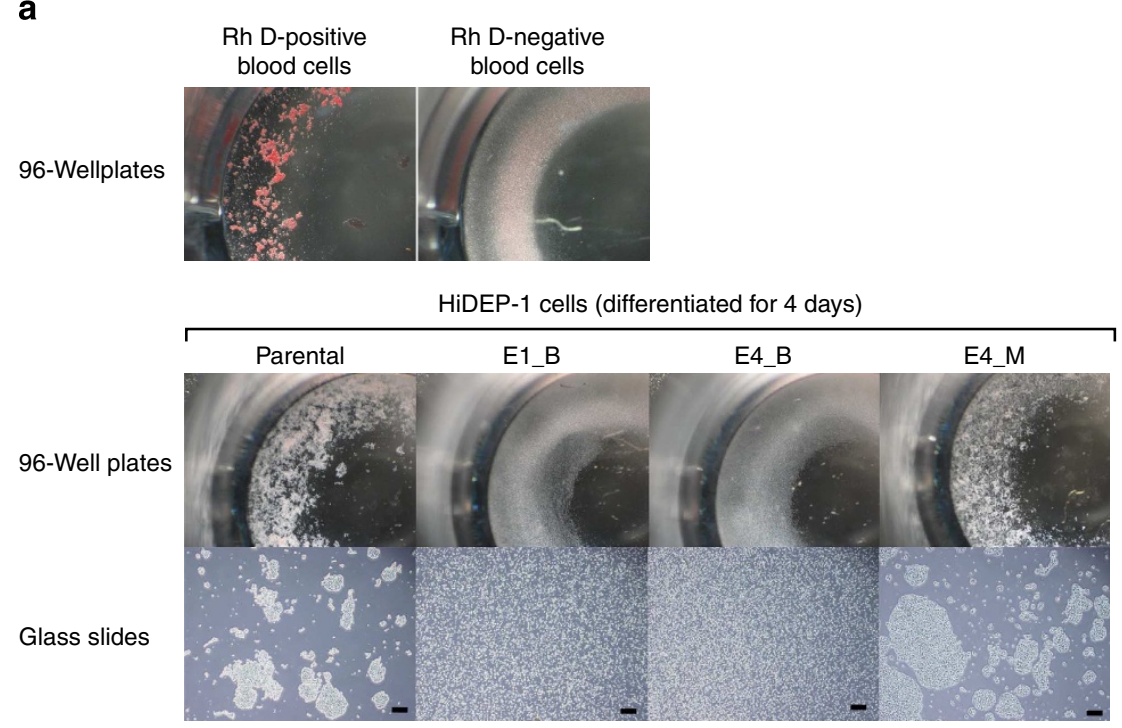

b

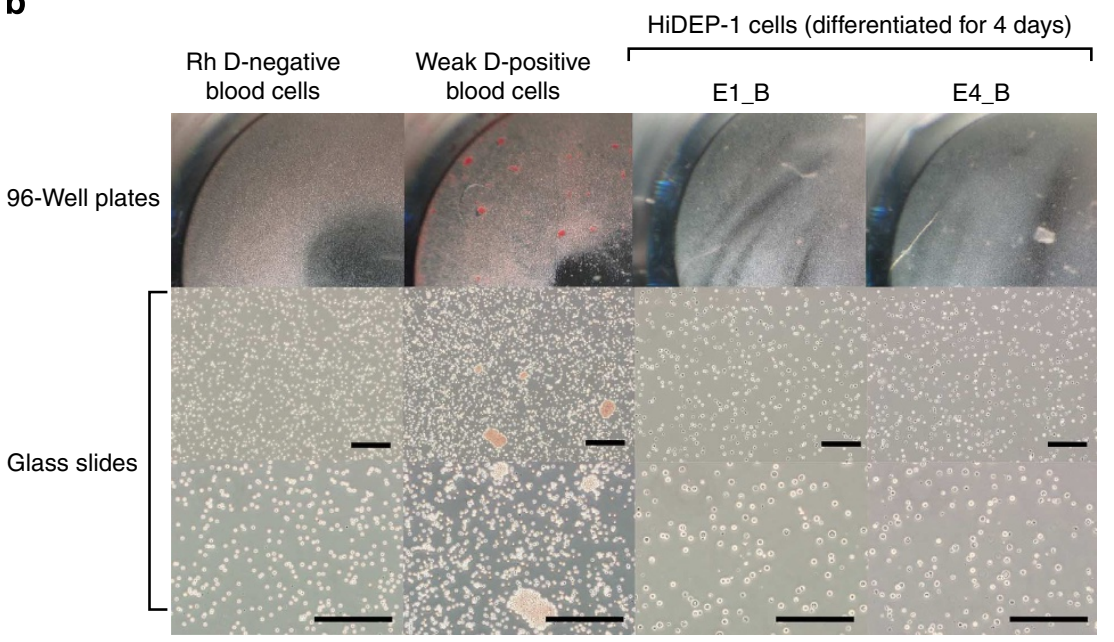

Figure 6 | Absence of D antigen-mediated agglutination in RHD-knockout cell lines. Parental, RHD-knockout (E1_B, E4_B) and RHD-monoallelic mutant (E4_M) HiDEP-1 cells were induced for differentiation for 4 days and subjected to an agglutination test using anti-D blood grouping reagents (a) and a weak D test using anti-D blood grouping reagents and Coombs' reagent (Anti-lgG, -C3d) (b) in 96-well plates and on glass slides. Rh D-positive, D-negative and weak D-positive human peripheral blood cells were used as the controls. A photograph and photomicrographs of each cell line are shown. Scale bar, $500 \mu \mathrm{m}$.

showed that, after the induction of differentiation, the expression levels of erythroblast markers such as glycophorin A and CD71 were similar between the parental and three mutant clones (Supplementary Fig.10), corroborating that RHD knockout does not affect differentiation. For a functional comparison between the parental line and three mutant clones, we measured their oxygen-carrying abilities. The oxygen binding and dissociation curves obtained were similar for each of these cell types (Fig. 7c), indicating that the TALEN-induced RHD mutation does not affect red blood cell function. Taken together, these results indicate that erythrocyte differentiation and oxygen-carrying functions are not affected by the TALEN-induced RHD mutation.

\section{Discussion}

Conversion of other blood groups into the $\mathrm{O} \mathrm{Rh} \mathrm{D}$-negative group has been studied in transfusion medicine for many years because universal donor blood cells can be transfused into patients when blood group-matched donor cells are not available or in an emergency situation when blood group determination cannot be readily achieved. The conversion of the A or B blood group into $\mathrm{O}$ has been accomplished using enzymatic reactions because $\mathrm{ABO}$ blood group determination depends on glycosyltransferase activity, the results of which can be reversed using available exoglycosidases ${ }^{1-4}$. However, similar enzymatic manipulations are not applicable to $\mathrm{Rh} \mathrm{D}$ blood group conversion because the Rh D blood group is determined by antigenic RHD protein expression, not by the activity of certain enzymes. Here we showed that TALEN-based disruption of RHD can convert homozygous dominant $\mathrm{Rh} \mathrm{D}$-positive cells into D-negative cells.

The main achievement of programmable nuclease-induced gene knockout to date has been the determination of the functions of genes ${ }^{24-26}$ and noncoding elements ${ }^{27-29}$ in cells or organisms. In addition, such gene disruption has also been utilized to treat human immunodeficiency virus infection ${ }^{30-32}$. Here, for the first time, we expanded the application of programmable nuclease-mediated gene disruption to blood group conversion.

Given that the different types of programmable nucleases share genome-editing abilities and mechanisms ${ }^{13}$, we can assume that 
a

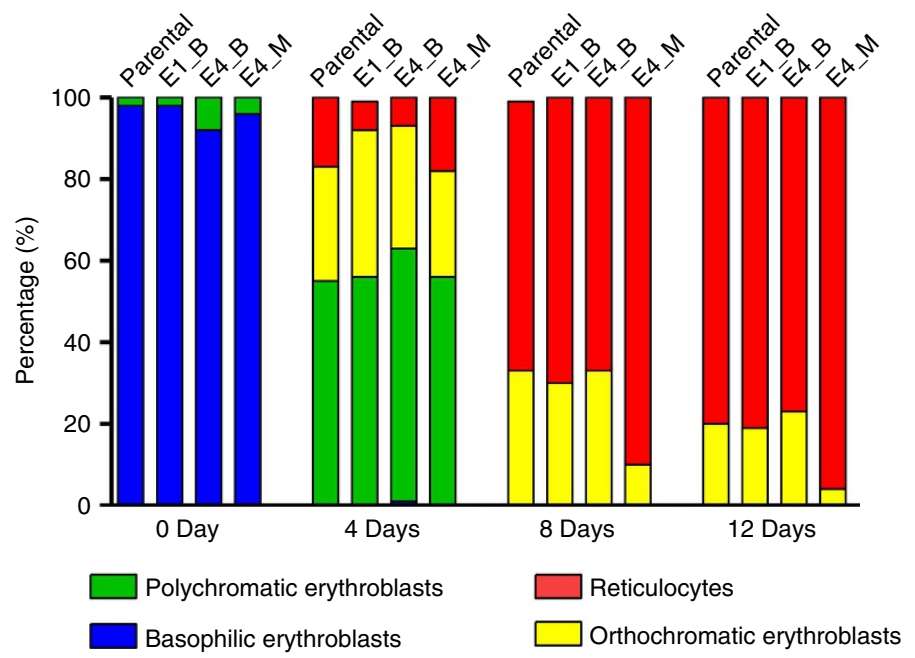

b

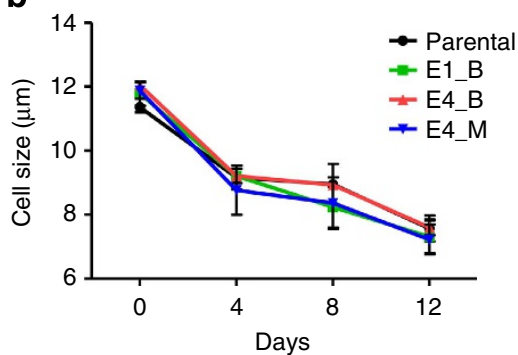

c

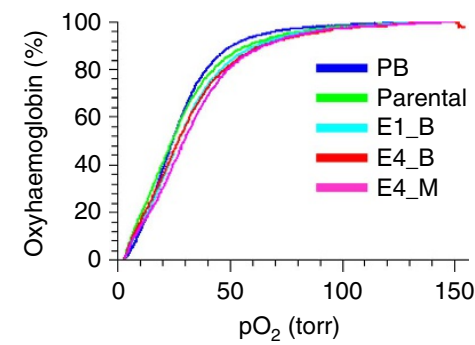

Figure 7 | The RHD mutation does not affect the differentiation and function of HiDEP-1. (a,b) At the indicated times after the induction of erythrocyte differentiation, differentiation of each HiDEP-1 cell line was quantified using microscopy after Wright-Giemsa staining. (a) Morphological analysis of differentiation. The sum of two independent experiments is shown. (b) Cell size during differentiation. ANOVA showed that the cell sizes were the same in the parental and RHD-mutant clones. Error bars represent the s.e.m. $n=3$. (c) Oxygen equilibrium curves of parental and RHD-mutant clones (E1_B, E4_B and E4_M). Human adult peripheral blood (PB) cells were used as the control.

conversion into Rh D-negative cells could be achieved using other programmable nucleases such as ZFNs and RGENs. Furthermore, our study also raises the possibility that programmable nucleasemediated gene editing could lead to blood group conversion in other blood group systems as well. For example, as the ABO blood group is determined by $A B O$, programmable nucleasemediated knockout of $A B O$ could lead to the generation of $\mathrm{O}$ blood-type cells from A, B or AB blood-type cells. Programmable nuclease-directed double knockout of $A B O$ and $R H D$ in erythroid progenitor cells or haematopoietic stem cells would enable the generation of $\mathrm{O} \mathrm{Rh} \mathrm{D}$-negative blood type, universal donor blood cells.

In the E1_B and E4_B clones, the absence of D antigen expression was validated using flow cytometry and agglutination assays. For E1_B, given that a significant amount of RHD mRNA was expressed and that the mRNAs contain PTCs in exon 1, the absence of $\mathrm{D}$ antigen would be attributable to PTC-induced translational termination or nonsense-mediated translational repression $^{33,34}$. This lack of $\mathrm{D}$ antigen expression in the presence of a significant level of RHD mRNA in E1_B is in contrast to the significant $\mathrm{D}$ antigen expression and reduced mRNA level in E4_M. The reduction of the RHD mRNA level in E4_M would be attributable to a lack of mRNA expression from the mutated allele, given that mRNA containing the mutation in exon 4 was not detected using mRNA sequencing. As the mechanism underlying this lack of mRNA from the mutated allele, we cannot rule out nonsense-mediated decay, although the mutation-induced PTC was 41 nucleotides upstream of the exon 4 terminus, which does not satisfy the '50-55 nucleotide rule ${ }^{35-39}$. In E4_B, aberrant splicing and a decrease in mRNA expression was observed. The aberrant splicing might be caused by mutation themselves or by nonsense-mediated alternative splicing, which was induced by PTCs that were generated by mutations. Given that the PTCs generated by the two mutations in E4_B cells satisfy the '50-55 nucleotide rule', the decrease in mRNA could be attributable to nonsense-mediated decay.

Although the D antigen was not detected using flow cytometry and agglutination assays in this study, we cannot rule out the possibility that our approach could lead to partial RHD protein expression. This partially expressed protein could still be antigenic, which could cause clinical problems, but might be hard to detect using antibody-mediated analyses such as flow cytometry and agglutination assays. In some cases, nuclease-induced mutations could create new epitopes as reported in previous studies in which mutations led to partial $\mathrm{D}$ expression ${ }^{40,41}$. Regarding such partial protein expression, genetic analysis or genomic DNA sequencing can reduce the false-negative rate of serological analysis ${ }^{42}$. If PTCs are in the transmembrane domain encoded by the RHD exon 1, expression of the extracellular region would be absent and, thus, the resulting protein would not cause clinical problems. In clone E1_B of this study, the PTCs are in the extracellular domain encoded by exon 1 and the resulting expected extracellular domain is only two and six-amino acids in length (Supplementary Fig. 6); such short regions have a low, if not zero, possibility of serving as antigens. For clone E4_B, we cannot rule out the possibility of potentially problematic partial expression of the first to third RHD extracellular domains because the PTCs are in exons 4 and 5 . 
Thus, the possibility of problematic partial protein expression may be reduced by the proper selection of clones, in this case by choosing clone E1_B instead of E4_B.

Compared with the previously reported enzymatic digestion of antigenic carbohydrate as a method for converting other blood groups into group $\mathrm{O}^{1-4}$, our approach has advantages and disadvantages. Our approach can be applied to progenitor or stem cells that can give rise to numerous erythrocytes. In vivo or ex vivo application of programmable nucleases to haematopoietic stem cells would lead to the generation of an almost unlimited number of erythrocytes with a converted blood group. However, such gene editing cannot be applied to enucleated mature erythrocytes, in contrast to enzymatic digestion. Given that the mechanisms for blood group conversion are different between the two approaches, they could potentially be combined to create a very effective system for converting blood groups.

The absence or extremely suppressed expression of $\mathrm{Rh}$ antigens can lead to $\mathrm{Rh}_{\text {null }}$ or $\mathrm{Rh}_{\text {mod }}$ disease, which is characterized with a mild to moderate haemolytic anaemia associated with stomatocytosis and plasma membrane abnormalities ${ }^{22,43}$. Because most of the differentiated cells in this study were reticulocytes, we could not determine whether RHD mutations cause stomatocytosis, although we did not observe any stomatocytes in the differentiated parental and mutant clones. $\mathrm{Rh}_{\text {null }}$ or $\mathrm{Rh}_{\text {mod }}$ disease can be caused by RHAG mutations alone or RHCE mutations combined with an $R H D$ deletion ${ }^{22}$. Using the two TALEN pairs in this study, the possibility of generating the RHAG mutation would be extremely low because potential offtarget sites were not found in RHAG. In the RHCE gene, potential off-target sites were found for both TALEN pairs. However, biallelic mutations in RHCE were found in only one clone out of the three RHD-mutant clones. These biallelic mutations were both in-frame, leading to minor changes (that is, one and two amino acid deletions) in Rh C, e, E or e antigens. Taken together, these observations suggest that the possibility of $\mathrm{Rh}_{\text {null }}$ or $\mathrm{Rh}_{\text {mod }}$ disease being caused by our approach would be low, although we cannot rule it out. To prevent such a disease, we can select $R H D$-mutant clones that do not have mutations in RHCE or use programmable nucleases that do not have off-target effects on RHCE.

Here we used Rh D-positive cells as a source for erythroid progenitor cells. Instead, one could use cells derived from an $\mathrm{Rh}$ D-negative donor as the source for erythroid progenitor cells, which would not necessitate the programmable nucleasemediated blood group conversion. However, for some ethnic groups, the availability of $\mathrm{Rh} \mathrm{D}$-negative donors matched for other minor antigens could be much lower than that of $\mathrm{Rh}$ D-positive donors matched for other minor antigens. Furthermore, the genetic diversity of the $\mathrm{RH}$ locus exceeds all estimates predicted by serology ${ }^{44}$, and $\mathrm{Rh}$ serologic phenotype-matched transfusion from minority donors does not prevent all cases of $\mathrm{Rh}$ alloimmunization in patients with sickle cell disease ${ }^{45}$. Thus, our approach of $\mathrm{Rh}$ antigen knockout would be a useful means of preventing alloimmunization.

In summary, here we showed that TALENs can induce the conversion of D-positive cells into D-negative cells by disrupting $R H D$, expanding the application of programmable nucleases into blood group conversion. This nuclease-based blood group gene editing opens new avenues for the development of methods for converting blood groups in transfusion medicine.

\section{Methods}

Cell culture. The Rh-positive blood group (homozygous dominant (DD)) erythroid progenitor cell lines HiDEP-1 and HUDEP-2 were derived from humaninduced pluripotent stem cells and human umblical cord blood cells, respectively ${ }^{19}$, and are available from Dr Yukio Nakamura (email: yukionak@brc.riken.jp) on request. We maintained these cells in a serum-free StemSpan SFEM medium (StemCell Technologies, Vancouver, BC, Canada), without feeder cells in the presence of doxycycline $\left(1 \mu \mathrm{g} \mathrm{ml}^{-1}\right.$; Sigma, St Louis, MO, USA), erythropoietin (EPO; $3 \mathrm{IU} \mathrm{ml}^{-1}$; CJ Phama, Seoul, South Korea) and dexamethasone $\left(10^{-6} \mathrm{M}\right.$; Sigma). Cord blood was collected from normal full-term deliveries in bags containing $24.5 \mathrm{ml}$ of citrate phosphate dextrose A (Green Cross Corp., Yong-in, Korea) under the approval of the Severance Hospital Institutional Review Board. Red blood cells were removed using Ficoll-PaqueTM PLUS (density, 1.077; GE Healthcare, Uppsala, Sweden) according to the manufacturer's instructions. CD34 ${ }^{+}$cells were isolated using a CD34 MicroBead Kit (Miltenyi Biotech, Bergisch Gladbach, Germany) according to the manufacturer's instructions. Cord blood $\mathrm{CD} 34^{+}$cells were induced to differentiate into the erythroid lineage for 17 days as follows ${ }^{23}$. From day 0 to 7 , sorted $\mathrm{CD}_{3}{ }^{+}$cells were continually cultured in serum-free culture medium supplemented with $100 \mathrm{ng} \mathrm{ml}^{-1}$ stem cell factor (Peprotech, Rehovot, Israel), $10 \mathrm{ng} \mathrm{ml}^{-1}$ interleukin-3 (Peprotech) and $6 \mathrm{IU} \mathrm{ml}{ }^{-1}$ recombinant EPO (Recormon Epoetin beta, Roche Diagnostic) with a half-volume medium change twice a week. Serum-free culture medium consisted of StemPro-34 SFM Complete Medium supplemented with 1\% bovine serum albumin (Sigma), $150 \mu \mathrm{g} \mathrm{ml}^{-1}$ iron-saturated human transferrin (Sigma), $50 \mu \mathrm{g} \mathrm{ml}^{-1}$ insulin (Sigma), $90 \mathrm{ng} \mathrm{ml}^{-1}$ ferrous nitrate (Sigma), $2 \mathrm{~mm}$ l-glutamine (Sigma), $1.6 \times 10^{-4} \mathrm{M}$ monothioglycerol (Sigma), $30.8 \mu \mathrm{M}$ vitamin $\mathrm{C}$ (Sigma), $2 \mu \mathrm{g} \mathrm{ml}^{-1}$ cholesterol (Sigma) and $1 \%$ penicillin-streptomycin solution (Gibco). In the second 7-day period of culture, the medium was replaced with serum-free culture medium with $3 \mathrm{IU} \mathrm{ml}^{-1}$ recombinant $\mathrm{EPO}, 50 \mathrm{ng} \mathrm{ml}^{-1}$ stem cell factor and $10 \mathrm{ng} \mathrm{ml}^{-1}$ interleukin-3 to induce cell expansion and differentiation. During days 15 to 17 of culture, only one cytokine (EPO, at $2 \mathrm{IU} \mathrm{ml}^{-1}$ ) was used for erythrocyte differentiation, and poloxamer 188 (Pluronic F68 (F68), Sigma; MW 8,400) was added at a concentration of $0.05 \%$. HEK293T (human embryonic kidney cell line) cells were cultured in DMEM (Gibco-BRL) supplemented with $10 \%$ fetal bovine serum (FBS, Gibco-BRL). Rh D-positive and Rh D-negative peripheral blood cells were supplied by Severance Hospital Blood Bank (Seoul, South Korea).

TALENs targeting RHD. TALENs targeting exons 1 and 4 of the $R H D$ gene were designed to include a $5^{\prime}$ thymine as the starting point of the TALE-binding sites ${ }^{26}$ (http://www.talenlibrary.net/); the plasmids encoding these TALENs were obtained from ToolGen (Seoul, South Korea). The maps and sequences of the plasmids are shown in Supplementary Note 1. These plasmids are available from Addgene, TALEN library resource (http://www.talenlibrary.net) and ToolGen (Order number H172187, H172190). The repeat variable diresidues used were NI, NN, NG and HD for binding to adenine, guanine, thymine and cytosine in the target sequence, respectively. The magnetic reporters were prepared as previously described $^{15}$. To evaluate TALEN activity, $3.0 \mu \mathrm{g}$ of TALEN plasmids (a plasmid encoding one TALEN and a plasmid encoding the other TALEN, each $1.5 \mu \mathrm{g}$ ) were transfected into 293T cells using FuGENE HD Transfection Reagent (Roche Diagnostics, Basel, Switzerland). After $72 \mathrm{~h}$ of transfection, cells were harvested and subjected to the T7E1 assay.

Generation of RHD-knockout clones. HiDEP-1 cells were transfected with a total $4.5 \mu \mathrm{g}$ of TALEN plasmids and reporters $(1.5 \mu \mathrm{g}$ plasmid encoding one TALEN, $1.5 \mu \mathrm{g}$ plasmid encoding the other TALEN and $1.5 \mu \mathrm{g}$ magnetic reporter plasmid) using a Human CD34 cell nucleofector kit (Lonza, Basel, Switzerland) from the Amaxa system. After incubation for 3 days at $37^{\circ} \mathrm{C}$, the transfected HiDEP-1 cells were mixed with magnetic bead-conjugated antibody against $\mathrm{H}-2 \mathrm{~K}^{\mathrm{k}}$ (MACSelect $\mathrm{K}^{\mathrm{k}}$ microbeads; Miltenyi Biotech) and incubated for $20 \mathrm{~min}$ at $4^{\circ} \mathrm{C} . \mathrm{H}-2 \mathrm{~K}^{\mathrm{k}+}$ cells were separated on a column (MACS LS column; Miltenyi Biotech) according to the manufacturer's instructions and seeded into 96 -well plates at 0.25 cell per well. The cells were cultured for 2 weeks and each obtained clone was transferred into 24-well plates for further expansion. $R H D$-knockout clones were identified using the T7E1 assay and sequencing.

T7E1 assay. Genomic DNA was isolated using a Genomic DNA purification Kit (Promega, Fitchburg, WI, USA) according to the manufacturer's instructions. Owing to the high homology between RHD and RHCE, we performed nested PCR using primers that bind specifically to RHD but not RHCE (Supplementary Table 1). The PCR amplicons were denatured by heating, annealed to form heteroduplex DNA, treated with 5 units of mismatch-sensitive T7 endonuclease 1 (New England Biolabs, Hitchin, UK) for $20 \mathrm{~min}$ at $37^{\circ} \mathrm{C}$ and analysed by $2 \%$ agarose gel electrophoresis. Mutation frequencies were calculated as previously described on the basis of the band intensities using the Image J software and the following equation ${ }^{46}$ : mutation frequency $(\%)=100 \times[1-(1-$ fraction cleaved $\left.)^{1 / 2}\right]$, where the fraction cleaved is the total relative density of the cleavage bands divided by the sum of the relative density of the cleavage bands and uncut bands. Uncropped images of gels shown in Figs $1 \mathrm{~b}, \mathrm{c}$ and $2 \mathrm{~b}$ and Supplementary Figs 3 and 6a,c are shown in Supplementary Figs 11a,b,12,13 and 14a,b, respectively.

Sequencing analysis. PCR amplicons were purified using a Fragment DNA Purification Kit (iNtRON biotechnology, Seongnam, South Korea) and cloned into the pGEM-T vector. Cloned plasmids were sequenced using a T7 primer (Supplementary Table 1). 
RT-PCR of RHD mRNA. Total RNA was extracted from cells using TRIzol reagent (Invitrogen, Carlsbad, CA, USA) according to the manufacturer's instructions and subjected to reverse transcription using Oligo-dT primer (Qiagen, Hilden, Germany) and AccuPower RT PreMix (Bioneer, Daejeon, South Korea) according to the manufacturer's instructions. The synthesized cDNA was subjected to PCR using a pair of primers (Supplementary Table 1). The PCR amplicons were analysed with $1 \%$ agarose gel electrophoresis and sequenced as described above. Uncropped images of gels shown in Fig. 4a are shown in Supplementary Fig. 15.

Induction of differentiation into erythrocytes. Differentiation into erythrocytes was induced by culturing the HiDEP-1 cells at $1 \times 10^{6}$ cells ml $^{-1}$ in erythroid differentiation medium; IMDM (Gibco-BRL) containing $10 \%$ human AB serum (Sigma), $\alpha$-tocopherol (20 $\mathrm{n} \mathrm{ml}^{-1}$; Sigma), linoleic acid (4 $\mathrm{ng} \mathrm{ml}^{-1}$; Sigma), cholesterol (200 $\mathrm{ng} \mathrm{ml}^{-1}$; Sigma), sodium selenite $\left(2 \mathrm{ng} \mathrm{ml}^{-1}\right.$; Sigma), holo-transferrin (200 $\mathrm{n} \mathrm{ml}^{-1}$; Sigma), human insulin (10 $\mathrm{\mu g} \mathrm{ml}^{-1}$; Sigma), D-mannitol (14.57 $\mathrm{mg} \mathrm{ml}^{-1}$; Sigma), mifepristone (an antagonist of glucocorticoid receptor, $1 \mu \mathrm{M}$; Sigma), and EPO $\left(5 \mathrm{IU} \mathrm{ml}^{-\mathrm{P}}\right)^{19}$.

Flow cytometry. Harvested cells were incubated with anti-D blood grouping reagent (human IgG/IgM monoclonal; Millipore, Billerica, MA, USA; dilution 1:10), antigen-presenting cell-conjugated anti-human-CD235a (BD Biocsciences, Franklin Lakes, NJ, USA; dilution 1:100) and phycoerythrin-conjugated antihuman IgG (Fc $\gamma$-specific; eBioscience, San Diego, CA, USA; dilution 1:100) in $100 \mu \mathrm{l}$ of staining medium (PBS (Sigma) containing 2\% FBS) for $20 \mathrm{~min}$ at room temperature. Stained cells were analysed using FACS Cantos II (BD Biosciences) and FlowJo (version X.0.7).

Morphological analysis. Cells $\left(1 \times 10^{5}\right.$ cells per slide) were centrifuged on slides using cytocentrifuge (Cytospin 4, Thermo Scientific, Waltham, MA, USA; $113 \mathrm{~g}$ (1,000 r.p.m.), $5 \mathrm{~min}$ ), stained with Wright-Giemsa dye (Sigma) and observed using a microscope (BX51; OLYMPUS, Tokyo, Japan) and a camera (DP71; OLYMPUS).

Agglutination assay. The differentiated HiDEP-1 cells and control red blood cells were plated into 96 -well plates at $1 \times 10^{6}$ cells per well in $10 \mu \mathrm{l}$ of PBS. Then, we added $10 \mu \mathrm{l}$ of anti-D blood grouping reagent to each well and incubated the cells for $15 \mathrm{~min}$ at $37^{\circ} \mathrm{C}$. Incubated cells were stirred using pipette tips and observed using a stereo zoom microscope (SZ61; OLYMPUS) and a camera (G10; Canon, Tokyo, Japan). For observation at higher magnification, the cell mixture was transferred to glass slides and observed using an inverted microscope (IX71; OLYMPUS) and a camera (DP70; OLYMPUS).

Clones that do not agglutinate in the presence of anti-D blood grouping reagents were subjected to a weak $\mathrm{D}$ test. We added $10 \mu \mathrm{l}$ of anti-D blood grouping reagent to Eppendorf tubes containing $2 \times 10^{6}$ cells in $10 \mu \mathrm{l}$ PBS and incubated the mixture for $15 \mathrm{~min}$ at $37^{\circ} \mathrm{C}$. After washing three times with PBS, the cells were mixed with $10 \mu \mathrm{l}$ anti-human IgG, -C3d (Ortho-Clinical Diagnostics, High Wycombe, UK), plated into 96-well plate, centrifuged for $30 \mathrm{~s}$ at $198 \mathrm{~g}$ (1,000 r.p.m.) and observed as described above.

Functional analysis of haemoglobin. After washing with PBS, $5 \times 10^{7}$ cells per group were subjected to the analysis. Oxygen equilibrium curves were determined using a Hemox-Analyzer (TSC scientific, New Hope, PA, USA) according to the manufacturer's instructions ${ }^{23}$. Human adult peripheral blood cells were used as the control.

Statistical analysis. All data were expressed as means \pm s.e.'s. Statistical analysis was conducted using IBM SPSS Statistics (version 21; IBM corporation, Armonk, NY, USA). ANOVA followed by multiple comparison with Bonferroni's method was performed. A $P$ value $<0.05$ was considered statistically significant.

\section{References}

1. Goldstein, J., Siviglia, G., Hurst, R., Lenny, L. \& Reich, L. Group B erythrocytes enzymatically converted to group $\mathrm{O}$ survive normally in $\mathrm{A}, \mathrm{B}$, and $\mathrm{O}$ individuals. Science 215, 168-170 (1982).

2. Vosnidou, N. C. et al. Seroconversion of type B to O erythrocytes using recombinant Glycine max alpha-D-galactosidase. Biochem. Mol. Biol. Int. 46, 175-186 (1998).

3. Bakunina, I. Y. et al. Alpha-galactosidase of the marine bacterium Pseudoalteromonas sp. KMM 701. Biochemistry (Mosc) 63, 1209-1215 (1998).

4. Liu, Q. P. et al. Bacterial glycosidases for the production of universal red blood cells. Nat. Biotechnol. 25, 454-464 (2007).

5. Landsteiner, K. W. A. An agglutinable factor in human blood recognized by immune sera for rhesus blood. Proc. Soc. Exp. Biol. Med. 43, 223 (1940).

6. Daniels, G. The molecular genetics of blood group polymorphism. Hum. Genet. 126, 729-742 (2009).
7. Le van Kim, C. et al. Molecular cloning and primary structure of the human blood group RhD polypeptide. Proc. Natl Acad. Sci. USA 89, 10925-10929 (1992).

8. Cherif-Zahar, B. et al. Localization of the human Rh blood group gene structure to chromosome region 1p34.3-1p36.1 by in situ hybridization. Hum. Genet. 86, 398-400 (1991).

9. Daniels, G. Human Blood Groups: Geoff Daniels; Foreword by Ruth Sanger 3rd edn. (John Wiley \& Sons, 2013).

10. Colin, Y. et al. Genetic basis of the RhD-positive and RhD-negative blood group polymorphism as determined by Southern analysis. Blood 78, 2747-2752 (1991).

11. Singleton, B. K. et al. The presence of an RHD pseudogene containing a 37 base pair duplication and a nonsense mutation in africans with the Rh D-negative blood group phenotype. Blood 95, 12-18 (2000).

12. Daniels, G. Variants of RhD--current testing and clinical consequences. $\mathrm{Br}$. J. Haematol. 161, 461-470 (2013).

13. Kim, H. \& Kim, J. S. A guide to genome engineering with programmable nucleases. Nat. Rev. Genet. 15, 321-334 (2014).

14. Kim, H., Um, E., Cho, S. R., Jung, C. \& Kim, J. S. Surrogate reporters for enrichment of cells with nuclease-induced mutations. Nat. Methods 8, 941-943 (2011).

15. Kim, H. et al. Magnetic separation and antibiotics selection enable enrichment of cells with ZFN/TALEN-induced mutations. PLoS ONE 8, e56476 (2013).

16. Ramakrishna, S., Kim, Y. H. \& Kim, H. Stability of zinc finger nuclease protein is enhanced by the proteasome inhibitor MG132. PLoS ONE 8, e54282 (2013).

17. Ramakrishna, S. et al. Surrogate reporter-based enrichment of cells containing RNA-guided Cas9 nuclease-induced mutations. Nat. Commun. 5, 3378 (2014)

18. Ramakrishna, S. et al. Gene disruption by cell-penetrating peptide-mediated delivery of Cas 9 protein and guide RNA. Genome Res. 24, 1020-1027 (2014).

19. Kurita, R. et al. Establishment of immortalized human erythroid progenitor cell lines able to produce enucleated red blood cells. PLoS ONE 8, e59890 (2013).

20. Kim, Y. H., Ramakrishna, S., Kim, H. \& Kim, J. S. Enrichment of cells with TALEN-induced mutations using surrogate reporters. Methods 69, 108-117 (2014).

21. Fine, E. J., Cradick, T. J., Zhao, C. L., Lin, Y. \& Bao, G. An online bioinformatics tool predicts zinc finger and TALE nuclease off-target cleavage. Nucleic Acids Res. 42, e42 (2014)

22. Avent, N. D. \& Reid, M. E. The Rh blood group system: a review. Blood 95, 375-387 (2000).

23. Jin, H., Kim, H. S., Kim, S. \& Kim, H. O. Erythropoietic potential of CD34+ hematopoietic stem cells from human cord blood and G-CSF-mobilized peripheral blood. Biomed. Res. Int. 2014, 435215 (2014).

24. Steentoft, C. et al. Mining the O-glycoproteome using zinc-finger nuclease-glycoengineered SimpleCell lines. Nat. Methods 8, 977-982 (2011).

25. Kernstock, S. et al. Lysine methylation of VCP by a member of a novel human protein methyltransferase family. Nat. Commun. 3, 1038 (2012).

26. Kim, Y. et al. A library of TAL effector nucleases spanning the human genome. Nat. Biotechnol. 31, 251-258 (2013).

27. Gutschner, T., Baas, M. \& Diederichs, S. Noncoding RNA gene silencing through genomic integration of RNA destabilizing elements using zinc finger nucleases. Genome Res. 21, 1944-1954 (2011).

28. Hu, R., Wallace, J., Dahlem, T. J., Grunwald, D. J. \& O'Connell, R. M. Targeting human microRNA genes using engineered Tal-effector nucleases (TALENs). PLoS ONE 8, e63074 (2013).

29. Kim, Y. K. et al. TALEN-based knockout library for human microRNAs. Nat. Struct. Mol. Biol. 20, 1458-1464 (2013).

30. Perez, E. E. et al. Establishment of HIV-1 resistance in CD4 + T cells by genome editing using zinc-finger nucleases. Nat. Biotechnol. 26, 808-816 (2008).

31. Holt, N. et al. Human hematopoietic stem/progenitor cells modified by zinc-finger nucleases targeted to CCR5 control HIV-1 in vivo. Nat. Biotechnol. 28, 839-847 (2010)

32. Maier, D. A. et al. Efficient clinical scale gene modification via zinc finger nuclease-targeted disruption of the HIV co-receptor CCR5. Hum. Gene Ther. 24, 245-258 (2013).

33. Lee, H. C., Oh, N., Cho, H., Choe, J. \& Kim, Y. K. Nonsense-mediated translational repression involves exon junction complex downstream of premature translation termination codon. FEBS Lett. 584, 795-800 (2010).

34. You, K. T. et al. Selective translational repression of truncated proteins from frameshift mutation-derived mRNAs in tumors. PLoS Biol. 5, e109 (2007).

35. Hwang, J. \& Kim, Y. K. When a ribosome encounters a premature termination codon. BMB Rep. 46, 9-16 (2013).

36. Behm-Ansmant, I. et al. mRNA quality control: an ancient machinery recognizes and degrades mRNAs with nonsense codons. FEBS Lett. 581, 2845-2853 (2007)

37. Chang, Y. F., Imam, J. S. \& Wilkinson, M. F. The nonsense-mediated decay RNA surveillance pathway. Annu. Rev. Biochem. 76, 51-74 (2007). 
38. Neu-Yilik, G. \& Kulozik, A. E. NMD: multitasking between mRNA surveillance and modulation of gene expression. Adv. Genet. 62, 185-243 (2008).

39. Maquat, L. E. Nonsense-mediated mRNA decay in mammals. J. Cell Sci. 118, 1773-1776 (2005)

40. Flegel, W. A. Blood group genotyping in Germany. Transfusion 47, 47S-53S (2007).

41. Flegel, W. A. Molecular genetics and clinical applications for RH. Transfus. Apher. Sci. 44, 81-91 (2011)

42. Rizzo, C. et al. Weak D and partial D: our experience in daily activity. Blood Transfus 10, 235-236 (2012).

43. Huang, C. H., Chen, Y., Reid, M. E. \& Seidl, C. Rhnull disease: the amorph type results from a novel double mutation in RhCe gene on D-negative background. Blood 92, 664-671 (1998).

44. Chou, S. T. \& Westhoff, C. M. Molecular biology of the Rh system: clinical considerations for transfusion in sickle cell disease. Hematology Am. Soc Hematol. Educ. Program 2009, 178-184 (2009).

45. Chou, S. T. et al. High prevalence of red blood cell alloimmunization in sickle cell disease despite transfusion from Rh-matched minority donors. Blood 122, 1062-1071 (2013).

46. Guschin, D. Y. et al. A rapid and general assay for monitoring endogenous gene modification. Methods Mol. Biol. 649, 247-256 (2010).

\section{Acknowledgements}

We are grateful to Jungwook Hwang (Hanyang University) for the helpful discussions. We thank Dong-Su Jang, MFA, (Medical Illustrator, Medical Research Support Section, Yonsei University College of Medicine, Seoul, Korea) for his help with the illustration of the cover art. This work was supported in part by the Korean Health Technology R\&D Project, Ministry of Health and Welfare, Republic of Korea (H10C1740 and
HI14C2019 (Medistar programme)) and the National Research Foundation of Korea (2014R1A1A1A05006189, 2008-0062287 and 2013M3A9B4076544).

\section{Author contributions}

H.K. and Y.-H.K. conceived and designed the experiments. Y.-H.K., H.O.K. and E.J.B. performed the experiments. H.K., Y.-H.K., H.O.K., E.J.B., R.K., H.-J.K. and Y.N. analysed the data. H.K. and Y.-H.K. wrote the paper.

\section{Additional information}

Supplementary Information accompanies this paper at http://www.nature.com/ naturecommunications

Competing financial interests: The authors declare no competing financial interests.

Reprints and permission information is available online at http://npg.nature.com/ reprintsandpermissions/

How to cite this article: Kim, Y.-H. et al. Rh D blood group conversion using transcription activator-like effector nucleases. Nat. Commun. 6:7451 doi: $10.1038 /$ ncomms 8451 (2015)

\section{(c) (i)}

This work is licensed under a Creative Commons Attribution 4.0 International License. The images or other third party material in this article are included in the article's Creative Commons license, unless indicated otherwise in the credit line; if the material is not included under the Creative Commons license, users will need to obtain permission from the license holder to reproduce the material. To view a copy of this license, visit http://creativecommons.org/licenses/by/4.0/ 


\title{
Corrigendum: Rh D blood group conversion using transcription activator-like effector nucleases
}

\author{
Young-Hoon Kim, Hyun O. Kim, Eun J. Baek, Ryo Kurita, Hyuk-Jin Cha, Yukio Nakamura \& Hyongbum Kim
}

Nature Communications 6:7451 doi: 10.1038/ncomms8451 (2015); Published 16 Jun 2015; Updated 22 Oct 2015

The original version of the Supplementary Information attached to this Article contained errors in the sequences of plasmids presented in Supplementary Note 1. The HTML has now been updated to include a corrected version of the Supplementary Information.

(c) (i) This work is licensed under a Creative Commons Attribution 4.0 International License. The images or other third party material in this article are included in the article's Creative Commons license, unless indicated otherwise in the credit line; if the material is not included under the Creative Commons license, users will need to obtain permission from the license holder to reproduce the material. To view a copy of this license, visit http://creativecommons.org/licenses/by/4.0/ 